\title{
Ambientalismo, Organizações Não Governamentais e a Busca pela Sustentabilidade no Turismo
}

\author{
Environmentalism, Non Governamental Organizations and the Search for Sustainability in \\ Tourism
}

Andrea Rabinovici ${ }^{1}$

\section{Resumo}

Neste artigo são discutidos conceitos de participação e sustentabilidade aplicados por ONGs atuantes na atividade turística, suas práticas no Brasil e o histórico deste debate. Discorre-se sobre as influências das ONGs ambientalistas para a sustentabilidade (ou não) do turismo e os conflitos sociais decorrentes de suas atividades nas localidades onde atuam. O texto deriva de tese de doutorado e se utiliza de suas conclusões, baseadas em dados coletados de nove ONGs estudadas (entrevistas semi-estruturadas, observação direta de atividades, fontes bibliográficas e documentais). Parte-se da hipótese de que o ambientalismo, através das variadas ONGs, investe no diálogo e nas articulações com atores diferenciados e por isso influencia fortemente o debate local sobre sustentabilidade socioambiental. Essa influência pode gerar novas desigualdades, enclaves e conflitos regionais, bem como novos graus de participação, empoderamento e reflexão dos atores sociais envolvidos.

Palavras-chave: ambientalismo; organizações não governamentais; sustentabilidade; turismo.

\section{Abstract}

This article discusses the concepts of participation and sustainability implemented by NGOs that are involved in tourism activities, its practices in Brazil and the history of this debate. The article addresses the influence of environmental NGOs towards the sustainability (or not) of tourism and social conflicts arising from their activities in the localities where they work. The text derives from a doctoral thesis and uses the thesis' conclusions, drawn from the data collected from nine NGOs studied (semi-structured interviews, direct observation of activities, bibliographic and documental sources). The article assumes that environmentalism, through various NGOs, invests in the dialogue and in joint efforts involving differentiated actors, strongly influencing therefore the local debate on social and environmental sustainability. This influence can generate new inequalities, disputes and regional conflicts, as well as new degrees of participation, empowerment and reflection of the involved social actors.

Keywords: environmentalism; non governamental organizations; sustainability; tourism.

\footnotetext{
${ }^{1}$ Cientista Social com ênfase em antropologia (UNICAMP), pós-graduada em Turismo Ambiental (SENAC, SP), Mestre em Ciência Ambiental (PROCAM-USP), Doutora em Ambiente e Sociedade NEPAM/UNICAMP e Professora da Universidade Federal de São Paulo - UNIFESP, Campus Diadema. Email: arabinovici@unifesp.br.
} 


\section{Introdução}

A II ${ }^{\mathrm{a}}$ Conferência Mundial para o Meio Ambiente e Desenvolvimento Sustentável (Rio-92) potencializou e popularizou no Brasil o significado das Organizações Não Governamentais $(\mathrm{ONGs})^{2}$ ambientalistas e a idéia de desenvolvimento sustentável. Desde então se observa a criação de um discurso sobre negócios sustentáveis, no qual o turismo ganha espaço, com projetos propostos por diversos atores sociais entre eles as ONGs.

Neste artigo é realizada a discussão sobre os conceitos de participação e sustentabilidade aplicados pelas ONGs atuantes na atividade turística, bem como o histórico deste debate e das suas práticas no Brasil. Afora isso se discorre sobre as possíveis influências das ONGs ambientalistas para a sustentabilidade (ou não) do turismo e os conflitos sociais decorrentes de suas atividades nas localidades onde atuam.

Este artigo é derivado da tese de doutorado de Rabinovici $(2009)^{3}$, e se utiliza das conclusões da pesquisa a partir dos dados das entrevistas semi-estruturadas com os responsáveis pelos projetos de turismo de nove $\mathrm{ONGs}^{4}$, da observação direta de suas atividades, além de fontes bibliográficas e documentais. As entrevistas visaram compreender os objetivos por trás da opção pela implementação da atividade turística em seu rol de projetos, bem como diagnosticar os conceitos de sustentabilidade e participação que moldam as ações de turismo. Também buscaram questionar indicadores de avaliação e monitoramento das atividades assim como a compreensão dos impactos e mudanças sociais que estas podem promover, inclusive novos conflitos socioambientais, através da reflexão feita pelos seus dirigentes, muitas vezes no momento da entrevista e na troca de idéias e informações com o pesquisador.

Partiu-se da hipótese de que o ambientalismo através das ONGs ambientalistas atuantes com

\footnotetext{
${ }^{2}$ Ressaltando sempre a heterogeneidade das ONGs e a dificuldade de se generalizar quaisquer coisas sobre elas por conta de suas diferenças.

${ }^{3}$ RABINOVICI, Andrea. Organizações Não Governamentais e Turismo Sustentável: trilhando conceitos de participação e conflitos. 2009. 340 p. Tese (Doutorado em Ambiente e Sociedade) - NEPAM - UNICAMP, Campinas, SP. Disponível em: $<$ http://libdigi.unicamp.br/document/?code $=000465869>$.

${ }^{4}$ Para tratar destas questões foram analisadas experiências de nove ONGs em sua atuação com turismo: Conservação Internacional- $\mathrm{Br}$ (CI-Br); Instituto Vitae Civilis (VC); Instituto de Desenvolvimento Sustentável Mamirauá (IDSM); Instituto Terramar e Amigos da Prainha do Canto Verde; Projeto Bagagem (PB); Instituto Peabiru (Peabiru); World Wildlife Fund (WWF) - Brasil; e Associação de Silves para Preservação Ambiental e Cultural (ASPAC). Neste artigo não serão apresentados dados específicos destas ONGs devido às limitações do formato. Apresentações sobre estas ONGs, as entrevistas e suas análises podem ser encontradas na tese Rabinovici (2009).
} 
turismo investe no diálogo e nas articulações com atores locais diferenciados e que o Estado brasileiro e a iniciativa privada pouco investem no turismo. Diante desse contexto, espera-se que as ONGs influenciem fortemente o debate local sobre sustentabilidade socioambiental e que essa influência possa vir a gerar novas desigualdades, enclaves e conflitos regionais, bem como novos graus de participação e empoderamento dos atores sociais envolvidos, incluindose aí as próprias ONGs e os demais envolvidos com a gestão dos recursos naturais. A convivência com os métodos, ferramentas e conceitos participativos, pode contribuir para desenvolver a crítica a esses processos, bem como permitir a compreensão acerca da heterogeneidade constituinte das entidades ambientalistas, facilitando a conquista da legitimidade nas suas iniciativas.

Autores como West, Igoe e Brockington (2006) observaram que as ONGs, ao apoiarem as estratégias mais comuns de conservação, tais como a implantação de Áreas Protegidas (APs), pioram os conflitos entre os grupos sociais locais, mudam práticas sociais, atribuem novos papéis às comunidades transformadas em atores sociais além de provocarem novos conflitos de gênero. O ecoturismo para eles é uma atividade conectada e simbiótica às APs. Segundo os autores, o ecoturismo trabalha para criar imagens simplistas da população local e dos seus usos e compreensões do ambiente.

Tal raciocínio pode ser expandido ao turismo e às ONGs que, geralmente são vistos pelas comunidades e sociedade em geral como salvadores, já que ambos, de alguma forma, prometem alternativas de mudança das realidades nas quais se inserem. Prometem novas formas de renda, de sobrevivência, de intercâmbio e de aprendizado social, empoderamento comunitário e diminuição de conflitos sociais. No caso do turismo e das ONGs que lidam com as questões ambientais, mais ainda, propõe-se à melhoria da qualidade ambiental, recuperação de áreas desmatadas, diminuição de impactos negativos sobre o meio ambiente entre muitos outros. No entanto, são vários os exemplos que contradizem que o turismo e as ONGs, seriam a salvação para as comunidades em localidades com atrativos naturais. A realidade observada, nas comunidades que tem programas de desenvolvimento turístico, nos mostra que, sob diversos aspectos, o turismo e o mau uso dos processos participativos podem ser ameaça e risco, ao invés de oportunidade, do ponto de vista social, laboral e ecológico (RABINOVICI, 2008a). 
Assim, constata-se que o turismo que se pretende sustentável e a ideia de participação são caminhos e pressupostos para a busca da qualidade de vida e eles orientam a prática dos princípios da sustentabilidade ambiental, propagados e perseguidos pelas ONGs e por demais atores. No entanto, as experiências concretas estudadas por Rabinovici (2009) demonstram que, para ser bem sucedido, além de seguir os passos recomendados à participação de fato, os projetos de turismo propostos por ONGs ainda têm que ser repensados em suas concepções e estratégias. Isto para não cair no limite apontado por Rahnema (1992) no qual a ideologização e o ideal predefinido de mudanças são tidos como motivadores das parcerias. Muitas ONGs se enquadram nessa perspectiva, o que é visível nos seus projetos iniciais que já determinam aonde chegar, o que alcançar, com qual prazo, estratégias e parcerias, sem dialogar com as comunidades-alvo. Portanto, antes de se autodeclarar participativo, parceiro e optar pelas ferramentas, o próprio conceito de participação precisaria ser amadurecido por todos os atores sociais envolvidos.

Outro aspecto crucial que limita a investida das ONGs no campo do turismo é o aprisionamento de todas as experiências à lógica mercadológica, capitalista. À medida que esta racionalidade impregna as propostas e objetivos das ONGs e até os sonhos das comunidades, pouco se pode alcançar em termos de avanços e conquistas, especialmente no que tange à inovação. Sendo que esta racionalidade econômica e tecnológica contrasta com a racionalidade ambiental (LEFF, 2001).

As ONGs ocupam papéis contraditórios nos projetos: buscam colaborar, mas, por vezes, acirram os conflitos já existentes, criam novas demandas e, com isso podem promover retrocessos extremamente complicados para as comunidades.

West, Igoe e Brockington (2006) ao estudarem os impactos sociais, materiais e simbólicos das APs sob os moradores dos seus entornos, afirmam que é decisiva a participação das ONGs nas transformações ocorridas. Estas mudanças são perceptíveis na reescrita da legislação restritiva das APs em nível mundial, na medida em que elas resignificam as formas das pessoas entenderem, experienciarem e usarem a natureza (a qual passa a ser chamada de meio ambiente) de forma separada da cultura, em uma nova cosmologia.

As ONGs também influenciam com seus discursos conservacionistas, os quais passam a permear o cotidiano local, podendo modificar as visões sobre meio ambiente por parte de 
alguns comunitários, o que, por sua vez, pode gerar inúmeros novos conflitos, na medida em que a apropriação dos discursos se dá de forma diferenciada por membros da comunidade, inclusive em função de sua sobrevivência. Esta nova apropriação do discurso conservacionista, por uma parcela da comunidade, passa a conflitar com outros discursos e práticas já arraigados por aqueles que mantêm atividades como caça e extração, e que passam a ser criminalizados pelas próprias comunidades.

\section{A Construção da Ideia de Sustentabilidade no Turismo}

Conceitos como os de sustentabilidade, desenvolvimento e participação permeiam as reflexões dos atores atuantes com o turismo que busca ser sustentável. Os impactos provenientes das atividades turísticas demandam questionamentos atentos que possam resultar em saltos qualitativos rumo ao aprimoramento do setor, em benefício dos envolvidos, no tocante aos aspectos culturais, ambientais, sociais e econômicos.

Para Irving e colaboradores (2005) a promoção da sustentabilidade no turismo requer uma concepção estratégica e duradoura de desenvolvimento amparada por um novo olhar sobre as questões sociais, culturais, ambientais dos destinos e aliadas e em interação com a economia globalizada. A sustentabilidade é tomada como referência.

Segundo Irving e Camphora (2005):

No turismo, a busca de sustentabilidade equivale à oportunidade de redimensionar espaços, paisagens, culturas e economias através de ações que qualificam o uso articulado de bens e serviços, gerando benefícios de ampla escala (IRVING e CAMPHORA, 2005, p. 311).

Para ser sustentável o turismo deve considerar como meta a manutenção da integridade dos processos ecológicos, biológicos, ambientais além de satisfazer as necessidades econômicas, culturais, éticas, estéticas das pessoas e dos ambientes envolvidos. Como ainda não se conhece nenhuma localidade onde tais variáveis tenham sido alcançadas, mesmo que parcialmente, a viabilidade da aplicação do conceito deve ser colocada, sob pena de cair em 
descrédito, enquanto conceito e utopia.

A sustentabilidade e o turismo têm um forte componente simbólico, abstrato e muito eficaz na promoção de ilusões sociais. Daí a necessidade de que, mesmo relativamente, existam exemplos concretos bem sucedidos nas várias experiências em andamento. Neste sentido é que as diversas vertentes do turismo caminham rumo ao discurso da inclusão social, da solidariedade e da responsabilidade. O impacto social de experiências bem sucedidas seria fundamental para continuar atraindo a todos em busca do re-encantamento.

A sustentabilidade deve ser assumida por todos os envolvidos na atividade, com suas responsabilidades específicas e definidas com o intuito de aprimoramento das condições de vida das pessoas e ambientes. Por este motivo, para as empresas do setor são fundamentais práticas coerentes com a minimização dos impactos negativos causados pela atividade, a continuidade dos projetos, a ética norteando as relações. Para as comunidades locais é mister a participação na definição dos rumos a serem perseguidos em conjunto com os demais atores, na decisão do quanto se quer resgatar e alterar em sua cultura e modos de vida. Para os turistas a responsabilidade auto-imposta sobre a sua presença, suas possibilidades de interação e trocas com ambiente natural e cultural visitado e com o coletivo que o espera na sua volta. Os demais profissionais, cada qual em suas especialidades, devem pensar e contribuir com a mitigação dos impactos negativos e descobrir as potencialidades e alcances das boas práticas de turismo.

Para além do gerenciamento dos impactos, Irving e colaboradores (2005) destacam a amplitude do planejamento para a sustentabilidade do turismo que tem potencial para gerar benefícios maiores por fazer uso de muita mão de obra e assim ajudar no combate ao desemprego estrutural. Por depender das paisagens e lugares bem conservados e ser uma oportunidade de diálogo multicultural o turismo parece ser alternativa concreta de sustentabilidade.

Pelo contato entre alteridades o turismo pode ajudar no aprendizado de práticas participativas de planejamento e condução das atividades, condições centrais da definição do turismo sustentável assim como a repartição dos benefícios gerados de modo equitativo entre os envolvidos. A capacitação, organização e empoderamento dos atores locais são de fundamental importância na medida em que parceria e diálogo devem acontecer com uma 
base comum de conhecimento que permita o diálogo. Tais premissas têm orientado projetos de ONGs, governos e até de empresas preocupadas com o sucesso de seus investimentos e têm norteado discussões polêmicas, sobre a certificação dos serviços turísticos ${ }^{5}$.

As diversas possibilidades e limites estão dados, há o consenso sobre sua necessidade e importância para qualificar como sustentáveis os processos, bem como a consciência da distância entre discurso e prática e de como, ainda, se tem poucas iniciativas bem sucedidas nesse campo.

Para Irving e colaboradores (2005):

Educar para o turismo é, portanto, condição para iniciativas duradouras e para a repartição de benefícios no desenvolvimento turístico. Assim, pensar sustentabilidade no turismo implica em idealismo e visão estratégica de longo prazo, mas também pragmatismo, a partir de experiências capazes de transformar utopia em possibilidade, discurso em prática cotidiana (IRVING et al., 2005, p.6).

Apesar do consenso sobre a imprescindível participação comunitária para a sustentabilidade do turismo, as dificuldades práticas, operacionais e metodológicas, muitas vezes, afastam os planejadores e implementadores de projetos da sua viabilização. As ONGs persistem nas iniciativas, mas muitas suspendem projetos por falta de recursos. A participação comunitária demanda grandes somas de dinheiro, recursos humanos bastante qualificados, metodologias ainda em estudo e com resultados questionáveis, além de serem de longo prazo, o que, muitas vezes dificulta ou impede a visualização concreta de resultados ou a própria avaliação deles. Exemplos de ONGs estudadas por Rabinovici (2009) mostram que a falta de respostas concretas e de sustentabilidade financeira dos projetos as impediu de dar andamento às experiências, mesmo que bem sucedidas sob outras perspectivas.

Nas estatísticas do turismo, não é possível a distinção entre o 'sustentável' e o 'insustentável'. O discurso político tende a privilegiar o 'sustentável', da mesma forma em que o pulveriza, em sentidos e significados diversos,

\footnotetext{
5 Para conhecer este assunto recomenda-se: SARACENI, Renata Fronza e NEIMAN, Zysman. 2010. Certificações na atividade turística. In: NEIMAN, Zysman e RABINOVICI, Andrea. (Orgs.). Turismo e Meio Ambiente no Brasil. Barueri, Manole, pp. 259-279.
} 
capazes de banalizá-lo, transformando-o em utopia contemporânea. Mas existe uma direção possível que transcende os imediatismos políticos e busca consolidar a participação cidadã, em escalas local e global. É nesse movimento cidadão que o turismo poderá se consolidar como veículo de transformação social, que transcende fronteiras políticas e atinge o campo da ética global (IRVING et al., 2005, p.7).

Turismo e ONGs estão em um mesmo movimento: ainda com muito a aprender, dotados de potencial para implementar novas dinâmicas e projetos, porém com grandes possibilidades de falhar. Ambos mexem com imaginação, com desejo, e não se furtam a isso. As críticas e as promessas não são ameaças. O caminho ideal perpassa a prática reflexiva contínua, capaz de assimilar os ensinamentos provenientes de todos os cantos. Essa tarefa, se bem conduzida, poderá extrapolar as promessas de salvação, na mesma medida em que elas são constantemente desconstruídas pela racionalidade vigente que as invalida taxando-as de utópicas.

Data dos anos de 1980 o início da prática e do debate das ONGs no Brasil, na questão da sustentabilidade no turismo, já existindo um caminho percorrido, como se verá a seguir.

\section{As ONGs Ambientalistas e a Sustentabilidade do Turismo}

A sustentabilidade no turismo é reconhecida como instrumento de conservação da natureza nos vários documentos globais, estando atrelada aos paradigmas ambientais de promoção da diversidade, de integração entre povos e sustentabilidade. Isso se dá através de ações e estratégias que buscam valorar a natureza, reconhecer limites de seu crescimento, buscar participação e emancipação social. O turismo é reconhecido como ferramenta de educação ambiental visando mudança de valores, comportamentos e atitudes dos envolvidos (NEIMAN, 2009).

Pode-se dizer que no turismo, de maneira geral, as empresas privadas mostram-se pouco comprometidas, praticando um turismo convencional esverdeado e cheio de contradições e incoerências, mesmo sem tocar no aspecto ético. Da mesma forma, os órgãos governamentais que contribuem com políticas e diretrizes, não acompanham o ritmo acelerado do crescimento 
da atividade, além de apresentarem descontinuidade nos projetos na troca de governos.

O tema da sustentabilidade do turismo vem à tona com popularização do seu segmento de natureza, a partir da década de 1980.

Especificamente o turismo conhecido como sustentável, ou ecoturismo (termo mais comum) foi fortemente impulsionado a partir da Rio-92, a qual popularizou as ONGs e o discurso sobre a conservação e desenvolvimento sustentável. Estes foram fundamentais e abraçados pelos ambientalistas sob a justificativa de que o turismo pode ser um grande propulsor da operacionalização pragmática deste discurso, como instrumento de conservação da natureza, atrelado aos paradigmas de promoção da diversidade, de integração entre povos e sustentabilidade.

Grandes expectativas foram depositadas na atividade a qual possuía diferentes definições, propostas e práticas provenientes de empresas privadas e dos órgãos governamentais. $\mathrm{O}$ turismo sustentável inicialmente se configurou como um turismo convencional, porém esverdeado e cheio de contradições e incoerências, bastante questionável em termos éticos em um contexto de demandas, expectativas e crescente popularização, enquanto atividade comercial e conservacionista.

Na década de 1990 as ONGs passam a se interessar pela atividade, participar em todos os fóruns dedicados à temática e a chamarem para si responsabilidades e atividades de ecoturismo, conquistando crescente espaço entre os demais atores sociais e políticos envolvidos.

Em 1996 a Organização Mundial do Turismo (OMT), o Conselho Mundial de Viagens e Turismo (WTTC) e o Conselho da Terra divulgaram a Agenda 21 para a Indústria de Viagens e Turismo e passaram a enfatizar e recomendar a necessidade de se formatar parcerias entre os três setores envolvidos com a questão turística.

Nestes documentos oficiais nacionais e internacionais as ONGs têm papel preponderante, seja em conjunto com o Estado e a iniciativa privada ou separadamente, visando à conservação da bio e sóciodiversidade, com participação e envolvimento em várias estratégias. Entre elas, destacam-se: envolvimento na proteção da natureza e da cultura de comunidades locais; 
controle da qualidade das atividades ecoturísticas; captação de recursos e financiamento; educação ambiental e sensibilização; intercâmbio de informações entre atores locais, regionais e globais; elaboração de diretrizes e de diagnósticos; capacitação e apoio à participação comunitária; na pesquisa e difusão de conceitos, métodos e técnicas; cogestão e apoio às APs e até com a operação da atividade ${ }^{6}$.

A presença das ONGs no desenvolvimento responsável do turismo foi corroborada no Acordo de Mohonk sobre Turismo Sustentável (2000), no qual se afirma que todas as ações dependem necessariamente da participação da sociedade civil, especialmente a representada pelas ONGs.

A Declaração de Quebéc (2002) traz recomendações específicas para as ONGs que atuam com o tema, legitimando-as como atores significativos. Tal documento apresenta uma seção inteira sobre as ONGs, repetindo inúmeras vezes a necessidade de parcerias e da colaboração destas entidades. Este documento, oficializado em Johanesburgo, na Cúpula Mundial sobre Desenvolvimento Sustentável (Rio+10), e que se constituiu em um elemento norteador das políticas internacionais, foi elaborado por especialistas em turismo, que incluem membros de ONGs.

Há no Brasil desde meados dos anos de 1990, certo investimento dos órgãos públicos para desenvolver o turismo sustentável, ao incluírem-no como meta nas agendas políticas. Estas metas, diretrizes e ações aparecem detalhadas em vários documentos, entre os quais se destacam: Diretrizes para uma Politica Nacional de Ecoturismo (1994), Diretrizes para a Politica Estadual de Ecoturismo- SP (1997), Programa de Desenvolvimento do Ecoturismo na Amazônia Legal (PROECOTUR) (1999) e os Pólos de Ecoturismo do Brasil (1998).

As iniciativas governamentais costumam ser pouco frequentes e descontínuas. Muitas vezes se resumem a criar e publicar diretrizes e projetos visando à sustentabilidade do segmento. Paralelamente há um mercado ecoturístico se expandindo, sem uma discussão mais abrangente envolvendo seus diversos atores sociais. Assim, a implementação das iniciativas ditas sustentáveis, se dá geralmente pelas ONGs (SERRANO, 2005).

\footnotetext{
6 Para maior detalhamento a respeito da contribuição das ONGs para o ecoturismo ver: RABINOVICI, Andrea e LAVINI, Carolina (2005).
} 
Essa pouca influência de políticas públicas e iniciativas privadas para a área conduz à participação de ONGs no setor, que passam a ter importância crucial no seu desenvolvimento, integrando os princípios e recomendações a práticas sustentáveis de turismo (LAVINI, 2002).

A entidade transnacional pioneira na atuação com turismo no Brasil foi o WWF-Br, que em 1971, iniciou suas ações com turismo, seguido por outras.

As ONGs passam a ser vistas como catalisadoras de ações em prol da conservação ambiental. Espera-se delas que sejam norteadas por preceitos e uma atuação democrática e participativa, em ações conjuntas com as comunidades locais na gestão do turismo. Que aceitem as comunidades como participantes e interlocutoras desta gestão, desde o começo dos trabalhos, e não somente legitimando-os após sua implementação (RABINOVICI e FERREIRA, 2008).

Desse início de trabalhos em parceria entre ONGs e comunidade é que será possível algum sucesso ou resistência, por parte dos comunitários, aos projetos. A resistência geralmente é observada após começarem as atividades, ou, a resistência é anterior quando há histórico de outras promessas não cumpridas por parte de ONGs.

Há sempre o ideal de se transformar as populações locais em sujeitos atuantes e inseridos na construção de pactos sociais e políticos. Nestes, a conservação dos recursos naturais pelas comunidades, os investimentos em qualificação profissional para sua gestão, a inserção no mundo global, o acesso a bens econômicos e culturais e o fortalecimento de identidades, seriam questões cruciais a serem atingidas, saindo do plano discursivo e complexo por definição.

\section{As Possíveis Contribuições das ONGs Ambientalistas para a Sustentabilidade do}

\section{Turismo}

Em diversos documentos são apontadas várias contribuições possíveis das ONGs para o turismo. Segundo Rabinovici e Lavini (2005) e Rabinovici (2009), geralmente remetem à: a) Proteção da natureza e da cultura local; b) Educação ambiental e sensibilização dos turistas e comunitários; c) Cooperação com os setores públicos e privados que desenvolvem atividades em APs e de alta biodiversidade; d) Integração das comunidades locais no planejamento 
participativo das atividades; e) Incentivo à integração entre os vários agentes participantes da atividade; f) Pesquisa sobre impactos, com posterior geração e difusão de informações; g) Capacitação de organizações e comunidades locais; h) Desenvolvimento de mecanismos para obtenção de recursos que possibilitem a perpetuação das políticas e planos desenvolvidos; i) Controle da qualidade da operação e certificação; j) Elaboração de diretrizes e de diagnósticos; k) Cogestão e apoio às APs através de seu desenvolvimento econômico; 1) Criação de Reservas Particulares do Patrimônio Natural (RPPNs) com potencial para influenciar a decisão de se implantar novas APs no seu entorno; m) Intercâmbio de informações entre atores de projetos locais, regionais e globais e; n) Inovações, reflexões, tendências, questionamentos para a área de turismo em geral.

As parcerias são fundamentais para atingir os ideais de sustentabilidade no turismo e, para as ONGs, representam um desafio constante (RABINOVICI e LAVINI, 2005). Porém, essas parcerias e a sua legitimidade devem ser questionadas em seus aspectos democráticos e participativos.

Estas atividades todas, quando praticadas, promovem aprendizado coletivo, fundamental para a viabilidade da sustentabilidade e da consecução dos objetivos propostos. As redes têm sido intensamente aproveitadas pelas ONGs e projetos de turismo espalhados por todos os países.

Talvez a maior contribuição esteja nas novas reflexões, tendências e filosofias propostas e exercitadas por algumas ONGs. Diferentemente de buscar agregar valor ou diferenciação de mercado, elas podem inovar, arriscar-se em direção a novos horizontes e propostas. As Organizações podem otimizar e realçar as experiências dos viajantes, dos anfitriões, repensar as mudanças e transformações sociais trazidas pela atividade, pelos contatos promovidos entre alteridades e, buscar alternativas de mitigação dos mesmos, seja na área ambiental, cultural, social ou econômica.

Há que se frisar que o ato de viajar pressupõe ao viajante sair da rotina, poder se distanciar do cotidiano, repensar o dia a dia e com isso tem potencial de provocar mudanças importantes e significativas no ambiente em que vive. A viagem pode, quando potencializada com propostas de vivências diversas promovidas pelos organizadores, no caso as ONGs, criar e testar novos métodos, propor novidades e criar tendências. Estas novas propostas trazem ao segmento a possibilidade de inovar e de repensar a sociedade, os destinos, os costumes, a modernidade e 
têm potencial para ativar mudanças sociais, na medida em que são experimentadas e aceitas por várias pessoas, com poder de modificar sua realidade e a de seu entorno.

As questões ambientais, sendo o assunto mais propagado desde o início do século XXI, têm despontado como um importante tema de debates para o turismo. No começo com a incorporação dos ditames e discursos da sustentabilidade e, depois com a necessidade ou até obrigatoriedade da inserção dos seus ideários as suas diversas práticas, que vão desde a mudança dos combustíveis das aeronaves, a busca por roteiros mais próximos que minimizem seu uso, até a procura por destinos não poluídos ou ameaçados pelas mudanças climáticas.

A disponibilidade para a troca de experiências, diálogo, convívio social com diferentes culturas, de pagar mais caro pelo que se supõe sustentável, até a possibilidade de convivência com a natureza e o descanso são outras questões que emergem. ONGs têm feito parcerias com empresas aéreas e de navios, hospedagem, agenciamento ou outras, para efetivar mudanças em suas políticas e práticas. Assim, estão sendo trabalhados projetos para o investimento em compensações ambientais, novos trajetos, revisão do consumo de combustível, embalagens, água, cuidados com o descarte de resíduos, plantio de árvores, modernização da frota e doação de dinheiro para institutos de pesquisas. Tais iniciativas, amplamente divulgadas pela mídia, estão comprometidas com a busca de soluções para mitigar os tais impactos negativos relacionados a estas questões. Pesquisas e diagnósticos e a comunicação deles são práticas comuns nas ONGs. Porém, nem todas as suas iniciativas promovem mudanças sociais e políticas consideradas benéficas, algumas de suas atividades rumam na direção da geração de novos conflitos e de mudanças consideradas negativas, como se verá a seguir.

\section{As Possíveis Contribuições das ONGs Ambientalistas para a Insustentabilidade do Turismo}

É interessante, ao se frisar as contribuições possíveis e desejadas das ONGs ao turismo, pensar sem maniqueísmos, que as elas também desencadeiam processos destrutivos, negativos ou simplesmente despertam novos conflitos que serão enfrentados pelas comunidades locais, o elo mais fraco nesta relação. 
A principal tensão começa, muitas vezes, quando as ONGs se colocam como agentes catalisadores de ações de conservação ambiental e assim oferecem seus projetos, arrecadam recursos financeiros e humanos e buscam parcerias. Consequência disso pode ser a desmobilização da comunidade que passa a depender da sua tutela, ou a incorporar uma agenda diferente da original, apostando em alternativas técnicas, sem sentido para elas. Alguns casos de comunidades com projetos de turismo implementados por ONGs estudados por Rabinovici (2009) confirmam a ocorrência do desmantelamento de iniciativas locais, com a dependência e acomodação comunitária na ONG.

Importante lembrar que os impactos negativos e positivos têm a mesma origem, a depender da condução dos trabalhos, com potencial ora desestruturador, ora estruturador da comunidade. A mudança produzida nas populações envolvidas nos projetos é intensa, sejam elas mudanças tidas como benéficas ou não, de acordo com quem as analisa. No tocante aos impactos concretos do turismo, a contribuição dos debates está na intervenção e problematização das ações que incidem nos territórios onde ele é praticado, com o potencial de transformar as populações locais em sujeitos atuantes e inseridos na construção de pactos sociais e políticos para a conservação dos recursos naturais. Além disso, investimentos em qualificação profissional para a gestão destes recursos, inserção no mundo global, acesso a bens econômicos e culturais e o fortalecimento de identidades, seriam metas para sair do plano discursivo e criar condições emancipatórias.

Segundo Campos (2006) as transformações socioambientais pautadas nas interações, ocorrem em todos os sentidos para os sujeitos envolvidos nos processos conflituosos. Assim os agentes externos, tais como as ONGs, influenciam e são influenciados. Criam-se tendências diversas de mudança, que podem resultar na manutenção e no abandono de práticas locais de manejo dos recursos naturais.

No turismo é comum observar mudanças significativas na percepção das comunidades de moradores, quando estas passam a conviver com diferenças, aceitando posturas totalmente contrárias as suas, valorizando determinadas paisagens e aspectos das culturas locais, correndo sempre o risco de folclorizá-las, criando ou tirando sua autenticidade, alterando radicalmente seus modos de vida, ou, aquilo que Yázigi (2001) denominou de 'Alma do Lugar'. 
Talvez seja por conta da questão empresarial que as experiências recentes de turismo ainda não avançaram em direção à sustentabilidade. Dirão os técnicos, que, com capacitação e tempo, as comunidades se adaptarão. Dirão as comunidades e algumas ONGs, que, por conta dessa racionalidade mercadológica e técnica, perde-se a sua essência, não só "atrativa" as olhares dos turistas, como no funcionamento e reprodução social e cultural, que, a longo prazo, inviabilizariam o turismo.

Essa tão propagada vertente empresarial recomendada às comunidades locais pelas ONGs que as assistem, na verdade, constitui a grande falácia das próprias ONGs, das nacionais às transnacionais.

Como então impor essa racionalidade sabendo que ela pode ser uma das causas principais do fracasso das iniciativas de turismo nas ONGs melhor estruturadas?

A racionalidade que se imagina em contextos complexos como este, com inter-relações sistêmicas, científicas, econômicas, sociais e políticas e que se constrói na articulação de outras esferas de racionalidade não considera a natureza dentro da racionalidade econômica, o que por si já seria insustentável. De acordo com Leff (2001) a solução estaria na busca de uma racionalidade ambiental visando uma estratégia produtiva na qual o ambiente se integre à lógica produtiva, agrupando os aspectos técnicos, humanos e sociais. Esta racionalidade é contrária a lógica do mercado e considera na gestão de recursos naturais a produção e a apropriação dos conhecimentos, saberes e valores culturais das comunidades (LEFF, 2001).

Percebe-se esta diferença quando as comunidades mostram dificuldades de se adaptarem e assimilarem a face mercadológica e a racionalidade proposta pelas ONGs, correndo-se o risco de interpretações preconceituosas, ou realistas, por parte dos técnicos destas. Esta lógica pode não fazer sentido aos comunitários, os quais podem já tê-la experimentado e a descartado. Podem, inclusive, ter tido ou conhecido experiências que conduziram à constatação de que preferem outro tipo de lógica, ou a sua própria, em detrimento da que está sendo proposta pela ONG. Isso é muito comum em destinos turísticos transformados pelo enorme impacto social e ambiental e que servem de maus exemplos às comunidades que passam a temê-los.

Muitas ONGs tutelam comunidades e, pode ocorrer que esta esteja vinculada a uma insegurança da própria ONG com relação à capacidade da comunidade em ser sustentável. 
Isso pode ter base real, concreta, ou preconceituosa, ou ainda, estar preso a interesses das ONGs proponentes que, mediante a tutela, poderão continuar trabalhando e sobrevivendo. Às vezes a manutenção desta é justificada em razão da avaliação da ONG ou de seu financiador, concluir que não houve o cumprimento das metas propostas e mensuradas por indicadores selecionados. Estes nem sempre são eficientes, inteligentes ou adequados à situação local, conduzindo a resultados questionáveis. Exemplo disso é o ato de considerar bem sucedido um projeto calculando somente seus ganhos financeiros que, devido aos altos investimentos que o turismo exige, podem demorar a aparecer. Medir somente uma variável pode significar abandonar conquistas maiores, dependendo do ponto de vista, como a politização e organização crescente da comunidade ou outros ganhos relevantes que não são levados em conta, taxando o projeto de mal sucedido e a comunidade de incapaz. Neste sentido, projetos são abandonados, prematuramente, pela interrupção do financiamento de patrocinadores preocupados somente com a dimensão econômica.

Isto tudo pode conduzir à perda da dimensão socioambiental ou simplesmente ao fim dos projetos em andamento, sem levar em conta sua amplitude e as consequências mais brandas, menos perceptíveis ou, até uma compreensão limitada do potencial educacional e irradiador das iniciativas a despeito do seu custo imediato. Também não considera os conflitos novos e, muitas vezes bastante complicados, com potencial desestruturador da comunidade.

Ainda prevalece nas ONGs uma visão muito limitada de turismo e de sustentabilidade. Obras e serviços mais convencionais que remetam ao turismo de massa podem ser uma imposição de uma lógica de mercado a uma atividade que pode superá-la e ainda assim ser sustentável. Isso, claro, quando se aposta nas consequências de um fazer que rume a uma mudança de visão de mundo e atitudes que esta prática pode propiciar, sem abrir mão de seus princípios, mas abusando da originalidade e da criatividade.

Devido ao condicionamento cultural pode-se exigir certo padrão de conforto e segurança; mas é preciso tomar cuidado para que isso não mascare, não encubra o medo de experimentar outras possibilidades de viver e de pensar. É preciso que o Ecoturismo deixe de "preparar" os locais para receber o visitante e passe a preparar o visitante para conhecer os locais. $\mathrm{O}$ ecoturista que for educado a compreender e conviver com a diferença saberá reconhecer a riqueza dessa experiência (MENDONÇA; NEIMAN, 2002, p.170). 
Essa visão estritamente comercial é a que pode culminar em uma postura equivalente à do mercado, identificada como turismo de massas, e assim levar ao fracasso da atividade, e, como consequências trazer uma marca de desilusão desnecessária. Do ponto de vista do turista, que irá se refletir no preparo da atividade pelas ONGs e comunidades:

Muitas vezes, um atendimento comumente considerado como "de qualidade" pode tornar a experiência do visitante totalmente previsível. Uma pousada com televisão e frigobar no quarto, um guia muito bem treinado, bem vestido e bem equipado, constituem serviços de qualidade como se espera que sejam, em qualquer lugar. Mas, se o visitante não sabe o que significa entrar em contato com a alma do lugar fica sem poder desejar essa experiência (MENDONÇA e NEIMAN, 2002, p.170).

Esta opção, de arriscar e propor vivências diferenciadas, não como um novo segmento ou nicho do mercado, mas como uma recuperação original do seu sentido, não foi bem sucedida nos projetos conhecidos de ONGs atuantes com o turismo. Isso demonstra que a aposta nessa atividade, tida como sustentável, tem que ser mais arrojada e fiel aos seus preceitos, sob pena de ser identificada com as contradições e problemas enfrentados pelo mercado. Assim, não haveria distinções entre as preocupações e possibilidades de atuação de ONGs, do trade turístico e do poder público.

A face mercadológica aparece como uma incoerência, ou, evidencia que a conservação ambiental é, de fato, prioridade. A aposta no turismo, realizada por ONGs estritamente conservacionistas, está condenada ao fracasso por desconsiderarem indicadores outros que priorizam conquistas importantes políticas, sociais, de aprendizagem, de empoderamento.

Além da concorrência com o mercado, a disputa entre as próprias ONGs gera uma série de novos problemas, tais como disputas por verbas para capacitar comunidades, capacitação sem estudos de demanda, frustrando os formados que ficam desempregados depois de tantos esforços.

As ONGs nem sempre consideram o momento, o ritmo e os aspectos culturais das comunidades em sua busca por autonomia, liberdade, participação e uso dos recursos. Seus projetos, questionados em sua legitimidade, podem acirrar disputas pré-existentes. 
As comunidades, muitas vezes, têm dificuldades em compreender o tempo dos projetos, e, como muitos deles demoram a ser negociados e implementados, de forma realmente participativa, elas tendem a se desiludir e desacreditar do projeto e da ONG. Este aspecto, no caso de pequenas ONGs, que de fato queiram implementar projetos negociados e participativos, pode ser fator crucial para a sobrevivência da parceria e dos projetos propostos.

Outro fator crucial para o acirramento dos conflitos é o desconhecimento de como superar as barreiras culturais para que ocorra diálogo produtivo para todos. Estudo de Rabinovici (2009) mostrou que seus entrevistados foram unânimes em citar os limites e as diferenças dos atores locais em trabalhar questões técnicas e mercadológicas do turismo.

As comunidades são capacitadas, mas, por mais que o sejam, geralmente os membros das ONGs não esperam que absorvam tudo, se equivalham aos mestres ou os superem. Há um limite claro do quanto se esperar das comunidades e que permita que a parceria seja duradoura ou permanente.

Mais motivos para o acirramento de disputas e conflitos são a questão financeira e de poder (inter-relacionadas) resultante da proximidade de membros da comunidade com as ONGs, especialmente dos comunitários que participam mais ativamente delas. Outro ponto de tensão são as diferenças entre visões e técnicas provenientes da interação entre especialistas, técnicos, comunidade e turistas diante das diferenças socioeconômicas entre comunitários e membros de ONGs e da imposição de novos pontos de vista e estilos e modos de vida distintos.

Problemas comuns na atividade turística podem resultar do incremento na renda de alguns comunitários envolvidos com o turismo, em detrimento de outros não aptos e/ou não interessados na atividade, especialmente quando o turismo oferece condições desiguais de emprego e renda, criando novas desigualdades, dando maior espaço para jovens e mulheres, realçando diferenças históricas de servidão, de raça ou outros aspectos.

Entre os impactos do turismo com grande potencial conflituoso, percebidos por Peralta (2005) em Mamirauá (AM), que tem forte presença de ONGs e de pesquisadores estão: as novas fontes de renda incentivando a permanência da população na área rural, bem como o crescimento populacional e migração de retorno o que, aumenta a pressão pelos recursos 
naturais e por isso há que se atentar por construir novas políticas de ocupação. A autora também constatou abalo nas relações de poder e intensificação da estratificação social entre as unidades domiciliares na medida em que são produzidas novas formas de hierarquia e fontes de poder. Esta situação muitas vezes culmina em processos de resistência ao turismo.

Peralta (2005) ressalta os possíveis impactos positivos que a atividade turística pode ter. Afirma que ela pode vir a ser um incentivo à conservação dos recursos naturais tão somente caso os moradores percebam, na proteção dos recursos, uma forma de geração de benefícios econômicos. Isso já ocorre em Mamirauá (AM), através de decisões comunitárias pautadas na socialização das perdas e dos ganhos da atividade, no envolvimento de todos no monitoramento e controle das atividades e no incentivo ao diálogo entre saberes locais e os técnico-científicos.

A mesma questão é apontada por Born (2002) quando insiste que comunidades que vivem em APs ou no seu entorno devam receber compensação por serviços ambientais:

Atividades como Ecoturismo ou agricultura orgânica ou em sistemas agroflorestais ainda não remuneram a população local, pois a sociedade em geral não quer pagar um preço justo por mercadorias e serviços que são oferecidos com o custo de proteger o ambiente, os monumentos históricos, a cultura e a paisagem (BORN, 2002, p.53).

A dependência da comunidade em relação à ONG e ao turismo, sendo a primeira teoricamente temporária e o segundo sazonal, pode trazer enormes problemas e desestruturação local. Muitas vezes a dedicação exclusiva ao turismo se revela como um dos piores impactos, pois pode incorrer no abandono de outras práticas geradoras de renda ou de subsistência, como no caso de pescadores que deixam de investir ou até de conhecer a atividade em função dos ganhos imediatos do turismo.

Uma questão citada por Rabinovici (2009) é a aposta ou priorização equivocada de temas menos importantes ou até sem sentido para as comunidades por parte dos projetos das ONGs.

À medida que os financiadores apóiam ONGs somente sob determinadas condições, por vezes são realizados projetos para atender aos editais e financiamentos que nada tem a ver com as demandas e interesses comunitários, ao menos os mais imediatos. Assim, caminhos iniciados 
pela comunidade são abandonados em função de outros menos interessantes ou, existe a possibilidade de que os projetos das ONGs consigam maior visibilidade do que os locais. Estes projetos locais, comumente, são citados pelas ONGs como ineficazes e ruins de modo a justificar os financiamentos, ofendendo sobremaneira a atuação local e minimizando as conquistas dos comunitários, garantindo até prêmios para a ONG em cima de projetos 'comunitários' desconhecidos pela comunidade.

Assim como impertinentes, há os projetos equivocados, apenas de interesse da ONG e não da comunidade, formatados para receber verbas.

No entanto, mesmo assim, o comum é que as ONGs tenham o status de salvadoras. No turismo promovem uma espetacularização em seus afazeres, tão superficial como a promovida pelas agências de turismo, deixando a cargo do marketing as maiores responsabilidades.

Assim para avançarmos rumo a algumas conclusões, deve-se retomar o debate sobre poder e participação, que é central quando se trata de projetos de parcerias entre sujeitos diferenciados: cabe às ONGs pactuar com comunidades, envolvê-las e serem envolvidas, não impor seus projetos sem anuência e real participação comunitária, deixando claro para todos, de que novos conflitos surgirão, de modo que o empoderamento e a possibilidade de lidar com eles de forma equilibrada, em termos de poder, são fundamentais.

\section{Conclusões}

Os casos estudados por Rabinovici (2009) exemplificam a emergência de novos conflitos nas localidades nas quais há atuação das ONGs com turismo. No entanto, é quase impossível saber o que ocorreria caso as ONGs não estivessem presentes, além da impossibilidade de se isolar a influência exclusiva delas das demais possíveis inspiradoras de mudanças sociais, como a mídia e a globalização.

O Ecoturismo, assim como um cavaleiro do apocalipse, não cavalga sozinho como anúncio de modernidade, mas vem junto a outros cavaleiros, como os movimentos sociais, a comunicação em massa e a urbanização (PERALTA, 2005, p.188-189). 
Os exemplos estudados também revelaram uma repetição constante de discursos, falas, estratégias em comunidades muito distintas culturalmente, em uma tentativa de se criar uma unidade capaz de articular, ordenar, organizar um aparato teórico de experiências bem sucedidas dentro de uma heterogeneidade de comunidades e de ONGs. A unidade em terrenos e identidades tão diferentes e a própria tentativa de consenso constituem elementos para criar ou acirrar conflitos.

A imposição de estratégias únicas, a sobrevivência e o sucesso dos projetos, comunidades e ONGs são fatores iniciais cruciais para os confrontos e sucessos das parcerias e projetos.

Por parte das ONGs há uma tentativa de produção de um arsenal teórico-prático único, orientado por influências, muitas delas, provenientes de fora do Brasil, com insuficiente adaptação a nossa realidade, mas fortemente identificadas com o momento histórico de aposta no turismo e no discurso da sustentabilidade como formas privilegiadas de conservação de APs.

É desse momento histórico internacional também que se constroem e se começa a praticar noções de autonomia comunitária, empoderamento e participação. A origem de todas estas práticas foram os diversos movimentos sociais da década de 1970 e 1980, que, combinados com a crescente profissionalização das ONGs, a partir da década de 1990, refletiram sobremaneira nas experiências citadas. Isto pode ser observado nas modificações dos critérios e formatos de financiamento e de novos indicadores pelas agências financiadoras, com a incorporação da variável da participação.

O turismo, a participação comunitária, a emancipação, a sustentabilidade são todos elementos com forte cunho simbólico e fantasioso, os quais resgatam o discurso da utopia, tanto em sua construção, como, ao contrário, por sua desconstrução. No caso da desconstrução, estas práticas funcionam como mais um elemento que comprova o fim das utopias (JACOBY, 2007) já que está repleto de exemplos de tentativas mal sucedidas, ingênuas e impossíveis de se concretizarem. Passa a somar às demais justificativas para o fim das utopias, como a própria crise ambiental, a civilizatória e a crise desenvolvimentista.

Em um momento de necessidade identificada de mudanças nas características dos 
financiamentos e nos indicadores, sendo as ONGs grandes pulverizadoras de projetos e influenciadoras de políticas públicas, uma reflexão como a provocada aqui, com indicativos propositivos ainda a serem testados, revela-se oportuna.

Essas experiências são concomitantes a um período no qual a profissionalização das ONGs é parte de um projeto de criação de suas identidades, da sua sobrevivência, com ONGs internacionais atuando no Brasil, com suas necessidades de reconhecimento e aceitação através de um processo de abrasileiramento', buscando legitimação de discursos (LYRA, 2005).

Os indicadores que dialogam diretamente com as linhas de financiamento, devem ser revistos por técnicos e comunidades por serem repetitivos, pouco eficazes e nem sempre pertinentes, especialmente quando aplicados pela própria comunidade, acostumada a monitorar impactos de forma mais intuitiva. Os manuais, idem: são esperados por todos como receita de felicidade e sobrevivência, mas por sua abrangência, acabam dizendo pouco a cada uma das realidades que os utiliza e tenta aplicar. Assim, acabam abandonados pelos comunitários antes de testados, ou, logo após a saída das ONGs 'de fora'.

A trajetória das ONGs é fortemente influenciada pelos financiadores, que impõem as condições para o fornecimento dos aportes financeiros e, a partir do estabelecimento das condições, as ONGs montam seus projetos nos diversos cantos do planeta. Além disso, ao serem dependentes dos financiadores, ficam vulneráveis e sujeitas, ONGs e comunidades, às crises internacionais.

Tendo como base que a autonomia buscada pelas comunidades deve ser a mesma desejada para as ONGs, estas devem dialogar com os patrocinadores a respeito da necessidade de uma revisão geral dos critérios de repasse de recursos financeiros, dos prazos, estratégias e indicadores. Devem apostar mais um pouco na idéia do turismo como potencial fonte de conservação dos recursos naturais e culturais de diversas comunidades, ao invés de abandonar a prática, conforme foi observado por Rabinovici (2008) no que se refere às grandes ONGs transnacionais no Brasil, que aqui deixaram de atuar e apostar no turismo, como se não houvesse potencial para a atividade.

Na medida em que houve avanços e ainda há claro potencial de mudança, mesmo a partir dos 
novos conflitos criados, muitos ainda desconhecidos ou pouco analisados pelas próprias ONGs, comunidades e financiadores, há que se buscar o ideal maior das ONGs. Este ideal ultrapassa o tema deste estudo, o turismo, e deve ser ampliado em direção aos ideais de mudança política, de cidadania e de justiça.

O turismo põe em destaque outros modos de vida. Apresenta e os divulga ao mundo. Terão os comunitários o desejo, a ambição e o poder de influenciar o resto da sociedade? Fariam isso quando, geralmente, são comunidades remotas e facilmente convertíveis ao projeto moderno apresentado pelas ONGs? Será que há sensibilidade das ONGs à questão das mudanças sociais e culturais? Terão as novas arenas, sociais e políticas, o potencial de construir pactos e acordos respeitosos, destacando a manutenção das diferenças? Quais serão as ferramentas e metodologias para que isso ocorra?

O caminho percorrido, as arenas formatadas, os atores amadurecidos, empoderados, os conflitos estabelecidos, poderão traduzir-se em novas tendências de participação, de turismo, de sustentabilidade, sem a perda das especificidades de cada um dos envolvidos, tal como acontece em um encontro de alteridades? Poderão subverter a lógica dominante? Colonizar os colonizadores em um processo inverso de exotização, tal como descrito por Sahlins (1997)?

Será que teríamos muitos opositores a um projeto mais radical e transformador de turismo? Quem seriam eles? As ONGs mais radicais podem provocar menos críticas do que as que se adaptaram ao neoliberalismo. A maioria das críticas mais exacerbadas, as que inclusive primam pelo tom conspiratório, são dirigidas exatamente às ONGs inseridas na lógica mercantil, confundidas com empresas, prestando serviços de governos, criticadas inclusive por outras ONGs... Às pequenas ONGs, tidas como radicais e revolucionárias são esquecidas pela comunidade, ou, de vez em quando, criticadas por não funcionarem profissionalmente, por seu caráter quase folclórico, seus ecochatos, militantes de esquerda, desempregados e inofensivos...

As pessoas amedrontadas com o futuro do planeta, sentindo falta da natureza, do prazer e do contato possível de ser trabalhado pelo turismo, fariam oposição a um projeto coerente de turismo que busca a sustentabilidade?

Este turismo, à medida que conseguir afrouxar os ditames e sua dependência do capitalismo, 
qual forma assumiria? Quais os tipos de pactos e atores necessários para tanta ousadia? Quantos novos conflitos ocorreriam?

Estas perguntas todas demonstram o quanto ainda há para se debater visando o aprofundamento da compreensão das mudanças sociais e culturais potencializadas pelo turismo e pelos projetos das ONGs.

De toda forma necessita-se observar a já constatada reação dos comunitários em relação aos projetos que os assistem. Seus interesses próprios vão sendo lapidados, amadurecidos, e, muitas vezes, opções como a de receberem projetos de cunho assistencialista são conscientes e livres.

A liberdade, as escolhas comunitárias e a melhoria da qualidade de vida (de acordo com os critérios de quem os vivencia) seriam os indicadores mais adequados para se avaliar o impacto das atividades em turismo e das ONGs sendo que:

A dimensão principal da avaliação das mudanças e dos papéis das mudanças em termos de melhoria de qualidade de vida deve ser em termos das capacidades dos indivíduos para levarem adiante seus planos de vida, ou seja, o grau de possibilidade que os indivíduos possuem em uma sociedade para escolher entre estratégias de vida. No caso das comunidades em questão, o Ecoturismo foi um instrumento da mudança que proporcionou aos moradores da área uma alternativa de escolha em resposta a ela: resistir, mudar ou moldar na forma que lhes convier. Isto é, a mudança em si é menos relevante do que a capacidade da comunidade e dos indivíduos de identificar e conduzir os caminhos que querem percorrer em resposta a estas mudanças: migrar para cidade ou não, trabalhar ou não, vender ou não, separar-se ou não, plantar ou não, pescar ou não. Existem escolhas que devem ser feitas. Para isso as comunidades devem continuar detendo o poder de decisão de seu próprio destino. Quando o Ecoturismo intensifica as capacidades da comunidade de escolher entre estratégias de vida, contribui para sua qualidade de vida (PERALTA, 2005, p.189).

Muitos praticantes, pensadores e proponentes de ONGs, acreditam no potencial revolucionário do turismo sustentável e partilham isso com comunitários, ou, têm a certeza de que está nas mãos deles a mudança, por isso também as expectativas são grandes e os cuidados redobrados. Seria bom evitar, partindo da experiência já acumulada, colocar em prática esboços de projetos fadados ao fracasso por causa dos mesmos erros passados. Tanta projeção e expectativas necessitam de criatividade, autonomia, liberdade e ousadia. 
Vale ressaltar que, nem as ONGs, nem o turismo constituem salvação para todas as mazelas das comunidades. Ao contrário, podem ser muito complicados somente por aparentarem ser a salvação. Causam todo tipo de impacto até quando nada de concreto é realizado, tal como os grandes projetos desenvolvimentistas ao serem anunciados, porém em uma escala espacial menor.

As ONGs ambientalistas são muito diferentes entre si, porém, ao decidirem trabalhar com turismo precisam estar cientes dos limites a serem encontrados ao proporem a conexão entre realidades muito diferenciadas e ao exporem comunidades a sonhos e projetos complexos e que mexem muito com o cotidiano e a orientação da sociedade.

Comunidades e sociedade civil como um todo estão, de certa forma, cada vez mais mobilizadas para não aceitar projetos e políticas públicas vazias e anseiam por conhecimentos e soluções que possam ser compartilhados. Nesse sentido, ONGs são potenciais parceiras, caso estejam abertas ao diálogo, pois as comunidades, cientes de sua força, têm a opção de buscar outros parceiros, sejam eles outras ONGs, empresas e governo.

De toda forma, considera-se muito especial o início do século XXI: vinte anos de grandes marcos e popularização do ambientalismo no Brasil e de experiências diversas em turismo em busca da participação e da sustentabilidade socioambiental. Resgatar as trajetórias percorridas pelas ONGs e comunidades em suas tentativas, já com certo volume de história passível de ser avaliado, repensado, reorientado, especialmente quando se sabe do potencial que as comunidades e ONGs têm para enfrentar todos os percalços e mudanças conjuntamente. Ainda há muito a realizar nas localidades onde ocorre o turismo e, apesar da quantidade crescente de conflitos, os mesmos têm orientado mudanças importantes e significativas que poderão levar a um salto qualitativo em seu conjunto de práticas e concepções. Poderão guiar também a criação de novos instrumentos e ferramentas de monitoramento e avaliação das mudanças sociais e a articulação dos interessados no diálogo produtivo que melhore a reflexão e as práticas do turismo que busca a sustentabilidade.

Somente o diálogo e a ação dos vários atores sociais organizados na busca de melhorias e ideais é que comporá um quadro capaz de reorientar a formação política, ambiental, tecnológica e mercadológica e de fazer do turismo, em todos os seus segmentos, algo sustentável. 


\section{Referências}

BORN, Rubens Harry. Compensação por serviços ambientais: sustentabilidade ambiental com inclusão social. In: BORN, R. H. Et al. (Org.) Diálogos entre as esferas global e local: contribuições de organizações não-governamentais e movimentos sociais brasileiros para a sustentabilidade, equidade e democracia planetária. São Paulo: Peirópolis, 2002, pp. 49-66.

CAMPOS, Simone Vieira de. A Influência de Atores Externos no Manejo de Recursos Naturais no Parque Nacional do Jaú, AM. $\{\mathrm{CD}\}$. Anais do III $^{\circ}$ ENANPPAS - Encontro da Associação Nacional de Pesquisa e Pós-Graduação em Ambiente e Sociedade, Brasília, DF, 2006.

IRVING, Marta de Azevedo, BURSZTYN, Ivan, SANCHO Altair. e MELO, Gustavo de M. Revisitando significados em sustentabilidade no planejamento turístico. Caderno Virtual de Turismo, Vol. 5, (4):1-8, 2005.

; CAMPHOHA, Ana Lúcia. A sustentabilidade como tendência no discurso turístico do Estado do Rio de Janeiro e Turista, o sujeito oculto da sustentabilidade. In: BARTHOLO, R; DELAMARO, M.; BADIN. L.. (Org.). Turismo e sustentabilidade no Estado do Rio de Janeiro. 1 ed. Rio de Janeiro: FAPERJ/ Garamond, 2005, pp. 309-328.

JACOBY, R. Imagem Imperfeita: Pensamento Utópico para uma Época Antiutópica. Rio de Janeiro: Civilização Brasileira, 2007.

LAVINI, Carolina. Ecoturismo e Terceiro Setor: atuação de ONGs ambientalistas do Estado de São Paulo. Trabalho de Conclusão de Curso (TCC) (Graduação em Turismo). Departamento de Relações Públicas, Propaganda e Turismo da Escola de Comunicações e Artes - USP, São Paulo, 2002.

LEFF, Enrique. Epistemologia ambiental. São Paulo, Cortez Editora, 2001. 240 p.

LYRA, Carla. Ação política e autonomia: a cooperação não-governamental para o desenvolvimento. São Paulo: Annablume; Terre des Hommes Suisse, 2005, 156p.

MENDONÇA, Rita; NEIMAN, Zysman. Ecoturismo: discurso, desejo e realidade. In: NEIMAN, Z. (Org.). Meio Ambiente, Educação e Ecoturismo. Barueri: Editora. Manole, 2002, 190p.

NEIMAN, Zysman. O contato intensivo com o ambiente natural do Parque Estadual Turístico do Alto Ribeira (PETAR, SP) como gerador de novas percepções. OLAM - Ciência \& Tecnologia, v. 9, 2009, p. 64-103.

PERALTA, Nelissa Bezerra. Os ecoturistas estão chegando - Aspectos da Mudança Social na RDS Mamirauá, AM. Dissertação (Mestrado em Planejamento do Desenvolvimento). UFPA, Pará, 2005.

RABINOVICI, Andrea. Organizações Não Governamentais e Turismo Sustentável: trilhando conceitos de participação e conflitos. 2009. 340 p. Tese (Doutorado em Ambiente e Sociedade) - NEPAM UNICAMP, Campinas, SP. Disponível em: $<$ http://libdigi.unicamp.br/document/?code=000465869>.

Organizações Não Governamentais, comunidades e turismo na Amazônia brasileira: conflitos e sustentabilidade. \{CD \} ST 1 - População Tradicional, Cultura e Conflito. Anais do Seminário Internacional Amazônia e Fronteiras do Conhecimento. Universidade Federal do Pará (UFPA), Núcleo de Altos Estudos Amazônicos (NAEA), Belém, PA, de 09 à 11 de dezembro de 2008.

Organizações não Governamentais e Turismo trilhando os conceitos de participação e 
sustentabilidade. $\{\mathrm{CD}\}$. Anais do $\mathrm{II}^{\mathrm{O}}$ Seminário Internacional de Turismo Sustentável 2008. Local: Fortaleza-CE, junho de 2008a.

; LAVINI, Carolina. ONGs: ecos de um Turismo Sustentável. In: MENDONÇA, R.; NEIMAN, Z. (Orgs.). Ecoturismo no Brasil. São Paulo, Ed. Manole, 2005, pp. 105-130.

; FERREIRA, Lúcia da Costa. Organizações Não Governamentais e Turismo Sustentável: participação e conflitos. $\{\mathrm{CD}\}$. Anais $\mathrm{IV}^{\mathrm{o}}$ ENANPPAS - Encontro da Associação Nacional de Pesquisa e Pós-Graduação em Ambiente e Sociedade, Brasília, DF, 2008. CD Room Mudanças Ambientais Globais: a contribuição da Anppas ao debate. Brasília, junho de 2008.

RAHNEMA, Majid. Participation. In: SACHS, W (Org.). The development dictionary. Zed Books Ltd. Londres, 1992.

SAHLINS, Marshal. O "pessimismo sentimental" e a experiência etnográfica: por que a cultura não é um "objeto" em via de extinção (parte II). Mana vol.3 n.2 Rio de Janeiro Oct. 1997. Pp. 103-150. Disponível em: $\quad<$ http://www.scielo.br/scielo.php?script=sci_arttext\&pid=S0104-93131997000100 002\&lng $=$ en\&nrm=iso $>$.

SERRANO, Célia Maria Toledo. Uma introdução à discussão sobre turismo, cultura e ambiente e a vida e os parques: proteção ambiental, turismo e conflitos de legitimidade em Unidades de Conservação. In: SERRANO, C.M.T.; BRUHS, H.T. (Org.). Viagens à natureza: turismo, cultura e ambiente. 7 ed. Campinas: Papirus, 2005, pp. 11-26 e pp. 103-124 .

WEST, Paige; IGOE, James; BROCKINTON, Dan. Parks and peoples: the social impact of protected areas. Annu. Rev. Anthoropol., 2006, 35:251-77. Disponível em: http://arjournals.annualreviews.org by CAPES. Acesso em: 16 jan. 2009.

YÁZIGI, Eduardo. A alma do lugar: Turismo, planejamento e cotidiano. São Paulo, Contexto, 2001.

\section{Recebido em: 21/07/2010 (1 ${ }^{\mathrm{a}}$ versão) $01 / 10 / 2010$ ( $2^{\mathrm{a}}$ versão)}

Aprovado em: 04/10/2010 